\title{
Risk Factors of Retinopathy of Prematurity Associated with Delayed Retinal Vascular Development
}

\author{
Ortega-Molina JM., Solans-Perez de Larraya A., ${ }^{1}$ Salgado-Miranda A., Jerez-Calero A., ${ }^{2}$ \\ Uberos-Fernandez J., ${ }^{2}$ Gonzalez Ramirez A. R., ${ }^{3}$ and García-Serrano JL., \\ ${ }^{1}$ Department of Ophthalmology. San Cecilio University Hospital, Granada, Spain \\ ${ }^{2}$ Department of Paediatrics, San Cecilio University Hospital, Granada, Spain \\ ${ }^{3}$ Biomedical Research Institute, ibs. Granada, University Hospitals in Granada, University of Granada, Spain \\ "Corresponding author: Jose Luis Garcia Serrano San Cecilio University Hospital Avda. Dr. Oloriz 16. Granada 18012, Spain. Tel: +34-651087488, E-mail: jopalace@hotmail.com \\ Received 2016 June 22; Revised 2017 February 13; Accepted 2017 April 25.
}

\begin{abstract}
Objectives: To assess risk factors of retinopathy of prematurity leading to delayed retinal vascularization in the first stage of ROP. Methods: A retrospective study (2000 - 2016) was performed in 275 infants who were born at a gestational age of $\leq 32$ weeks. Delayed vascular development was calculated as the difference in avascular area measured in terms of disc diameters between patients with risk factor and those with no risk factor.

Results: Intrauterine fetal demise of one twin, apnea, exchange tranfusion and intubation days ( $\geq 10$ days) lead to delayed retinal vascularization of $1.74,1.58,1.17$, and 1.11 disc diameters and of 3.35, 3.04, 2.25 and 2.13 weeks respectively. Delayed retinal vascular development was less than 1 disc diameter in other factors such as HS-PDA, sepsis, degree of hyaline membrane $\geq$ III, cerebral hemorrhage, birth weight (every $100 \mathrm{~g}$ less), gestational age (every week less), postnatal weight gain (every $1 \mathrm{~g}$ less/day) and cerebral hemorrhage. However, since these factors are quantitative (birth weight, gestational age and postnatal weight gain), the greater the adverse effect, the greater the delay will be.

Conclusions: Intrauterine fetal demise of one twin, apnea, exchange tranfusion and intubation days ( $\geq 10$ days) lead to delayed retinal vascular development more than 1 disc diameter at 4 - 6 weeks of postnatal life.
\end{abstract}

Keywords: Retinopathy of Prematurity, Angiogenesis Modulating Agents, Risk Factors

\section{Background}

The development of retinopathy of prematurity (ROP) involves multiple factors including neonatal immaturity (gestational age, birth weight), hyperoxia, low nutrient supply, intrauterine fetal demise of one twin, apnea and PDA (1-6).

Numerous cytokines are involved in the development of retinopathy of prematurity (7). The most important cytokines are: vascular endothelial growth factor (VEGF) and erythropoietin (EPO), which act as factors inducing neovascularization, and IGF-1, which acts as a permissive factor (3, $4,8)$. New mediators in ROP have been proposed including ATP/ADP. ATP has a double role in vascularization, as a main factor in the transfer of energy and as a coupling neurotransmitter of the vascular and brain systems $(9,10)$.

There are animal models of oxygen-induced retinopathy (OIR). ROP is a two-phase disease. The first phase begins with delayed retinal vascularization, followed by a second phase of vascular proliferation. In the initial phase of this model, delayed retinal vascular development occurs partly due to a decrease in ATP levels (1).
Premature infants have incomplete vascularization of the retina with a peripheral avascular area (11). The lack of nutrients or energy may lead to a delay in vascular and neural development. The total energy delivered to the retina in order to supply these ischemic areas depends on the blood flow, the oxygen concentration and the substrate concentration in the blood (12-14).

Our objective was to study the risk factors that determine a further delay in the vascularization of the temporal peripheral retina.

\section{Methods}

A total of 275 premature infants were studied retrospectively between 2000 and March 2016 following our hospital protocol for ROP. The data were collected prospectively from the inclusion of premature infants in said protocol to the completion of the ophthalmologic monitoring, by medical discharge or death $(15,16)$.

The degree of retinopathy in each eye studied was determined via indirect ophthalmoscopy with indentation and after pharmacological mydriasis by an expert ophthal- 
mologist in this technique, using for this purpose a 20diopter lens. This lens provides a magnification of 2.5 , allowing a $45^{\circ}$ view of the retina, the equivalent of 8 disc diameters (DD) $(5,17)$.

The avascular area of the temporal peripheral retina of premature infants measured in DD was evaluated in the first eye examination of ROP ( 4 - 6 weeks of postgestational age). Thus, we determined the extent of the avascular area.

The risk factors studied were sex, cesarean section, maternal age, single or multiple birth, maternal hypertension, surfactant administration, birth weight (every $100 \mathrm{~g}$ less), gestational age (every week less), postnatal weight gain (every $1 \mathrm{~g}$ less/day), degree of hyaline membrane $\geq$ III, HS-PDA, sepsis, cerebral hemorrhage, intrauterine fetal demise, apnea, exchange transfusion and intubation days ( $\geq 10$ days).

Intrauterine fetal demise of one twin was defined as the intrauterine death of one fetus in a twin pregnancy (deaths associated with fetal syndromes were excluded). This situation increases the risk of morbidity and mortality for the surviving co-twin due to hypoperfusion and tissue ischemia $(18,19)$.

Apnea was defined as a cessation of respiratory air flow for 20 seconds or longer, regardless of the clinical consequences or episodes of cessation of breathing of shorter duration which have cardiocirculatory repercussions (bradycardia and/or hypoxemia) (20).

ROP examinations in premature infants cause episodes of apnea, bradicardia or hypoxia. Therefore, the sickest premature infants with apnea are sometimes excluded from examination for one week, following pediatrician's advice, due to high risk of fetal distress (21). This study included exclusively those premature infants with severe apnea whose eye examination was postponed due to high risk of fetal distress.

This study only included premature infants with hemodynamically significant patent ductus arteriosus (HS-PDA), that is to say, premature infants with symptoms and/or left-right shunt diagnosed by Doppler echocardiography (pulmonary/systemic flow ratio > 1.5 - 2) (22-24). Examinations were carried out by the same pediatric cardiologist using cardiovascular ultrasound Acuson SC2000TM. All patients were treated with indomethacin at a usual dose of $0.2 \mathrm{mg} / \mathrm{Kg} / 24 \mathrm{~h}$ for 3 days or ibuprofen at an initial dose of $10 \mathrm{mg} / \mathrm{Kg}$ for the first day and $5 \mathrm{mg} / \mathrm{Kg}$ for the second and third day. There is no evidence that the pharmacological treatment of PDA is an added risk factor for ROP.

Exchange transfusion was used as a therapy for severe hyperbilirubinemia in preterms newborns despite intensive phototherapy and in all preterms with bilirubin encephalopathy symptoms.

Sepsis was defined as a positive fungal or bacterial blood culture with the additional criterion of the presence of generalized infection symptoms and hematologic findings.

Delayed vascular development was calculated as the difference in the avascular area measured in DD between patients with risk factor and those with no risk factor adjusted to the same gestational age in weeks.

In order to determine the existence of correlation between delayed retinal vascular development and significant risk factors for the total of 275 premature infants, bivariate analysis was carried out using the statistical package IBM-SPSS V.21.0 (SPSS Inc, Chicago, IL, USA). The ShapiroWilk test or the D'Agostino-Pearson omnibus test was applied to verify that the analyzed quantitative variables followed a normal distribution. The chi-square test was used to compare the proportions between groups, and if it failed to satisfy the conditions of validity, then the Fisher exact test was applied.

For comparison of differences in mean values between two groups, the Student t-test was applied after analysis of variance by means of the Levene test or the nonparametric Mann-Whitney U-test. The association between continuous variables was analyzed using the Pearson correlation coefficient or the nonparametric Spearman correlation coefficient.

\section{Results}

\subsection{Demographic Characteristics of the Study Population}

From the total of 275 premature infants, there were 139 (50.5\%) males and 136 (49.5\%) females. The mean gestational age and birth weight was 29.68 (SD 2.0) weeks and $1234($ SD = 319) g, respectively.

\subsection{Delayed Retinal Vascular Development Asocciated with Risk Factors of ROP}

In the group without fetal twin demise (group without the risk factor), we studied if there was a correlation between the avascular area measured in DD and the gestational age. This correlation was found to be statistically significant $(\mathrm{P}<0.001)$. Each additional week determined an average vascularization of $0.52 \mathrm{DD}$. Constant of correlation coefficient was 20.23 .

Disc $\emptyset=20.23-0.52\left(G^{*}\right.$ in weeks at the first eye examination)

Disc $\emptyset$ : Disc diameters yet to be vascularized in the temporal area of the retina

${ }^{*}$ GA: gestational age

In the first postnatal examination, premature infants with intrauterine fetal demise of one twin had an avascular area of $4.8 \mathrm{DD}$ in the temporal retina. When no fetal death 
occurred, preterm infants had an avascular area of 2.26 DD. Avascular area was significantly larger in cases of intrauterine fetal demise (Student t: 7.28, gl 11, P=1.8 E-6).

The group without intrauterine fetal demise of one twin was examined at a gestational age of 34.37 weeks on average and in the group with single fetal death, the surviving co-twins were examined at a gestational age of 32.83 weeks $(34.37-32.83=1.54$ weeks $)$.

We adjusted the first eye examination to the same gestational age: $1.54 \times 0.52=0.8 \mathrm{DD}$. If eye examinations were carried out at the same gestational age in both groups, the result would have been $2.26+0.8=3.06$ (Figure 1 )

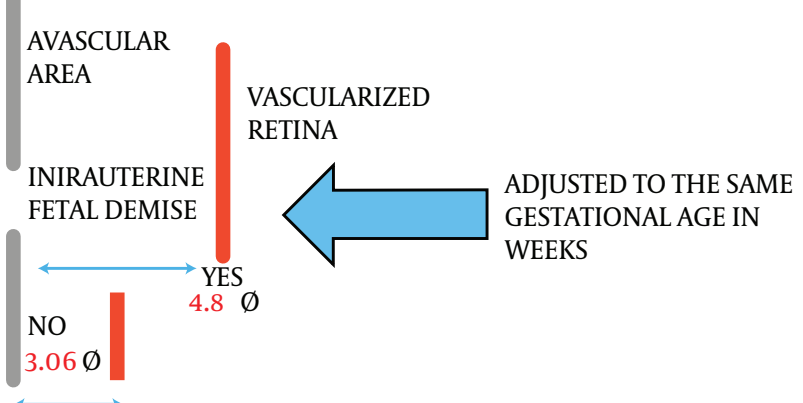

Figure 1. Avascular Area in the first examination of ROP at the same Gestational Age in Weeks is larger in cases of Intrauterine Fetal Demise of One Twin

In order to calculate the DD of delayed retinal vascular development in the first eye examination, we subtracted 3.06 from 4.8, obtaining a result of 1.74 DD. The weeks of delayed retinal vascular development in the first eye examination were calculated dividing 1.74 by 0.52 , obtaining a result of 3.35 weeks in the group with fetal twin demise.

Vascular delay in premature infants asociated with other risk factors was calculated using the same procedure. No delayed retinal vascularization was found in some of the risk factors studied such as sex, cesarean section, maternal age, single or multiple birth, maternal hypertension and surfactant administration.

In other factors, delayed retinal vascular development was less than $1 \mathrm{DD}$ such as HS-PDA $0.93 \mathrm{DD}$, sepsis 0.83 $\mathrm{DD}$, degree of hyaline membrane $\geq$ III $0.81 \mathrm{DD}$, cerebral hemorrhage $0.75 \mathrm{DD}$, gestational age (every week less) 0.69 $\mathrm{DD}$, birth weight (every $100 \mathrm{~g}$ less) $0.40 \mathrm{DD}$ and postnatal weight gain (every $1 \mathrm{~g}$ less/day) $0.13 \mathrm{DD}$.

Finally, other factors showed a retinal vascular delay greater than 1 DD: intrauterine fetal demise 1.74 DD, apnea 1.58 DD, exchange transfusion 1.17 DD and intubation days ( $\geq 10$ days) $1.11 \mathrm{DD}$ (Table 1 and Figure 2 ).
Table 1. The Age at First Eye Examination (Weeks in Average) and Delayed Vascular Development Indicated as Disc $\emptyset$ and in Weeks

\begin{tabular}{lccc}
\hline & $\begin{array}{c}\text { First eye } \\
\text { examination } \\
\text { (Weeks } \\
\text { average) }\end{array}$ & $\begin{array}{c}\text { Delayed } \\
\text { Vascular } \\
\text { Development, } \\
\text { Disc diametrs }\end{array}$ & $\begin{array}{c}\text { Delayed } \\
\text { Vascular } \\
\text { Development, } \\
\text { Weeks }\end{array}$ \\
\hline $\begin{array}{l}\text { Intrauterine } \\
\text { fetal demise of } \\
\text { one twin }\end{array}$ & 5.82 & 1.74 & 3.35 \\
\hline $\begin{array}{l}\text { Apnea } \\
\text { Exchange } \\
\text { transfusion }\end{array}$ & 5.37 & 1.58 & \\
\hline $\begin{array}{l}\text { Intubation } \\
\text { days }(\geq \mathbf{1 0} \\
\text { days) }\end{array}$ & 4.82 & 1.17 & 3.04 \\
\hline
\end{tabular}

\section{Discussion}

Examination of vascular development measured in DD was carried out by a single pediatric ophthalmologist following the same parameters in all premature infants. It is a subjective assessment method which may place limitations on our study. However, the eye examination devices currently used such as RetCam® prevent from examining with sufficient definition the periphery of the retina in a large number of cases, therefore, they would not be quantifiable. We defend this examination method pending the emergence of new recording devices which allow more accurate examinations of the retina in infants with ROP.

New factors which have an impact on the pathogenesis of ROP are currently being considered such as genetic components, nitric oxide, adenosine, apelin and $\beta$-adrenergic receptor $(10,25)$. The pathologies that we have studied may increase stress and fetal hypoxia and consequently, adenosine levels. In fact, the activity of adenosine is higher where oxygen demand is higher, such as in the retina $(10,26)$.

In the first stage of ROP, the obliterative phase, from birth to week 31 of gestational age approximately, a delay in retinal vascular development occurs. In the second stage of ROP, the vasoproliferative phase, pathological compensatory mechanisms appear, causing aberrant retinal vascularization. Incomplete retinal vascularization is the basis on which ROP is developed. The largest area of immature avascular retina will produce a greater angiogenic stimulus, which will increase the risk of ROP type 1, and therefore, there will be a greater risk of unfavorable result (4).

According to the International classification of ROP, Zone I consists of a circle whose radius extends from the optic disc to twice the distance from the optic disc to the center of the macula, which is equal to $6.5 \mathrm{DD}(27,28)$. Zone II extends peripherally from the edge of Zone I to a tangential point in the nasal ora serrata. The radius of this circle 


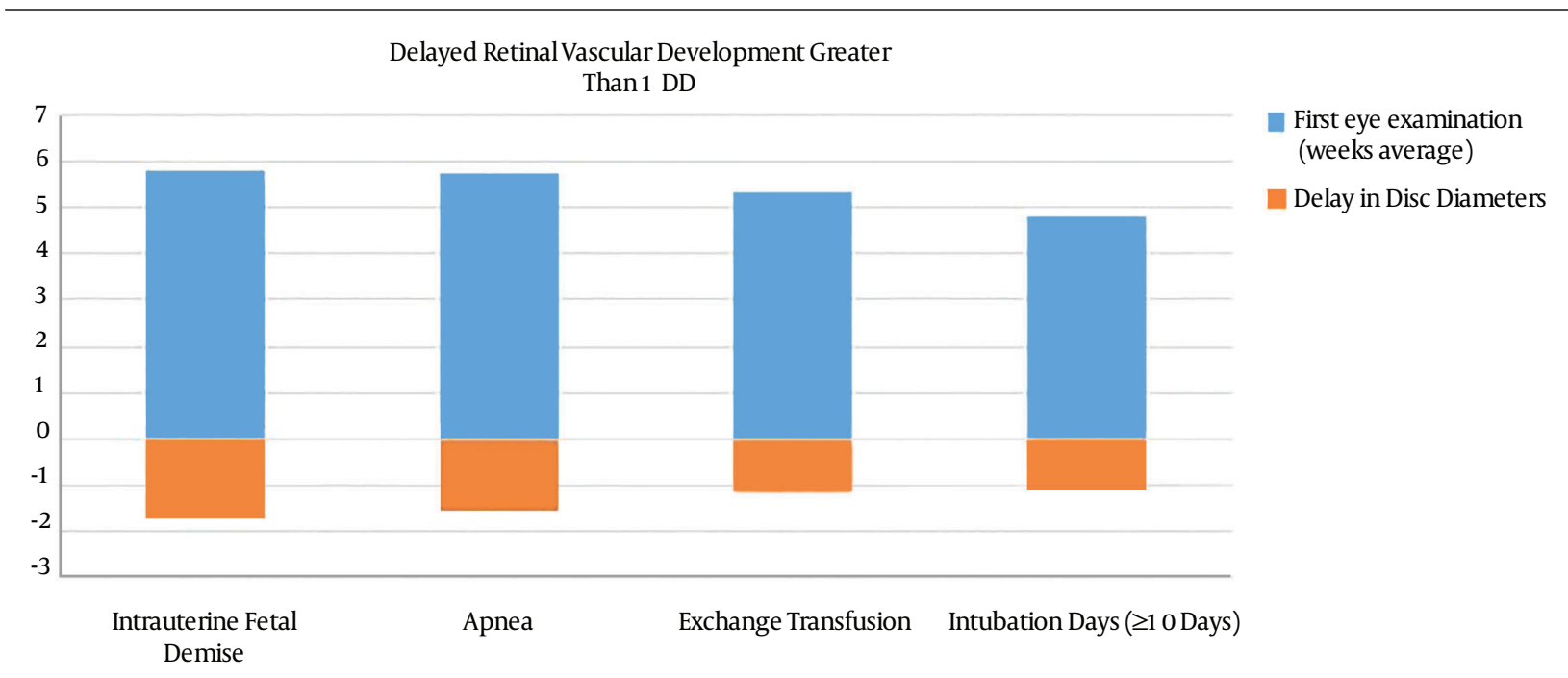

Figure 2. Delayed Retinal Vascularization in Disc Diameters in Patients with Risk Factor (Intrauterine Fetal Demise, Apnea, Exchange Transfusion and Intubation Days)

from the optic nerve is equal to $12 \mathrm{DD}$. Zone III is the residual crescent of the temporal retina anterior to Zone II. The radius of this circle from the optic nerve is equal to $14 \mathrm{DD}$.

At the same gestational age, those premature infants with retinal vascularization reaching Zone I have an increased risk of threshold ROP than premature infants with retinal vascularization reaching Zone II and III (29). Furthermore, premature twins with a smaller area of vascularized retina have a higher risk of severe ROP (30).

It is well known that hyperoxia is responsible for Phase I of ROP, where the retina experiences delayed vascular development secondary to hypoxia-inducible factor (HIF) down-regulation, and thus, VEGF is not released. We found that many factors may be involved in this Phase I of ROP, causing a greater delay in vascular development (31).

Recent studies report that the postnatal growth pattern is associated with morbidities (bronchopulmonary displasia, necrotizing enterocolitis and gestational age at birth) (32). According to these conclusions, we have found that some morbidities in preterm infants may lead to a delay in retinal vascular development.

Among all the factors studied intrauterine fetal demise, apnea, exchange transfusion and intubation days, $\geq 10$ days cause a greater delay in retinal vascular development.

Other factors studied are HS-PDA, sepsis, degree of hyaline membrane $\geq$ III, cerebral hemorrhage, birth weight (every $100 \mathrm{~g}$ less), gestational age (every week less) and postnatal weight gain (every $1 \mathrm{~g}$ less/day). All of them are associated with delayed vascular development lower than 1 DD. However, since these factors are quantitative (birth weight, gestational age and postnatal weight gain), the greater the adverse effect, the greater the delay will be. The effect of these factors is additive every week less, every 100 $\mathrm{g}$ or $1 \mathrm{~g} /$ day less respectively.

In our study, we found a delay in retinal vascularization higher than 1 DD at 4 - 6 weeks of postnatal life in patients with fetal twin demise, apnea, exchange transfusion and intubation days ( $\geq 10$ days). This delay is significant since it leads to a larger ischemic area in the first stage of ROP. Therefore, vascular reactivation is increased during the second stage of ROP, resulting in a more advanced stage of ROP.

\section{Acknowledgments}

We thank the pediatric hospital service of San Cecilio University hospital. This article is part of the Doctoral Thesis of Jose Maria Ortega Molina, within the Doctoral program in clinical medicine and public health, Granada University Spain.

\section{References}

1. Hwang JH, Lee EH, Kim EA. Retinopathy of Prematurity among Very-Low-Birth-Weight Infants in Korea: Incidence, Treatment, and Risk Factors. J Korean Med Sci. 2015;30 Suppl 1:S88-94. doi: 10.3346/jkms.2015.30.S1.S88. [PubMed: 26566363].

2. Poets CF, Roberts RS, Schmidt B, Whyte RK, Asztalos EV, Bader $\mathrm{D}$, et al. Association Between Intermittent Hypoxemia or Bradycardia and Late Death or Disability in Extremely Preterm Infants. JAMA. 2015;314(6):595-603. doi: 10.1001/jama.2015.8841. [PubMed: 26262797]. 
3. Hellstrom A, Smith LE, Dammann O. Retinopathy of prematurity. Lancet. 2013;382(9902):1445-57. doi: 10.1016/S0140-6736(13)60178-6. [PubMed: 23782686].

4. Hartnett ME. Pathophysiology and mechanisms of severe retinopathy of prematurity. Ophthalmology. 2015;122(1):200-10. doi: 10.1016/j.ophtha.2014.07.050. [PubMed: 25444347].

5. Garcia-Serrano JL, Ramirez-Garcia MC, Pinar-Molina R. [Retinopathy of prematurity in multiple births: risk analysis for plus disease]. Arch Soc Esp Oftalmol. 2009;84(4):191-8. [PubMed: 19384759].

6. Ghaseminejad A, Niknafs P. Distribution of retinopathy of prematurity and its risk factors. Iran J Pediatr. 2011;21(2):209-14. [PubMed: 23056789].

7. Sato T, Kusaka S, Shimojo H, Fujikado T. Simultaneous analyses of vitreous levels of 27 cytokines in eyes with retinopathy of prematurity. Ophthalmology. 2009;116(11):2165-9. doi: 10.1016/j.ophtha.2009.04.026. [PubMed: 19700197].

8. Can E, Bulbul A, Uslu S, Bolat F, Comert S, Nuhoglu A. Early Aggressive Parenteral Nutrition Induced High Insulin-like growth factor (IGF-1) and insulin-like growth factor binding protein 3 (IGFBP3) Levels Can Prevent Risk of Retinopathy of Prematurity. Iran J Pediatr 2013;23(4):403-10. [PubMed: 24427493].

9. Sapieha P, Joyal JS, Rivera JC, Kermorvant-Duchemin E, Sennlaub F, Hardy P, et al. Retinopathy of prematurity: understanding ischemic retinal vasculopathies at an extreme of life. J Clin Invest 2010;120(9):3022-32. doi: 10.1172/JCI42142. [PubMed: 20811158].

10. Cavallaro G, Filippi L, Bagnoli P, La Marca G, Cristofori G, Raffaeli G, et al. The pathophysiology of retinopathy of prematurity: an update of previous and recent knowledge. Acta Ophthalmol. 2014;92(1):2-20. doi: 10.1111/aos.12049. [PubMed: 23617889].

11. Chen J, Stahl A, Hellstrom A, Smith LE. Current update on retinopathy of prematurity: screening and treatment. Curr Opin Pediatr. 2011;23(2):173-8. doi: 10.1097/MOP.ob013e3283423f35. [PubMed. 21150442].

12. He JH, Zhang J. Fifth dimension of life and the $4 / 5$ allometric scaling law for human brain. Cell Biol Int. 2004;28(11):809-15. doi 10.1016/j.cellbi.2004.07.011. [PubMed: 15563403]

13. Lofqvist C, Engstrom E, Sigurdsson J, Hard AL, Niklasson A, Ewald U, et al. Postnatal head growth deficit among premature infants parallels retinopathy of prematurity and insulin-like growth factor-1 deficit Pediatrics. 2006;117(6):1930-8. doi: 10.1542/peds.2005-1926. [PubMed 16740833].

14. Downie LE, Hatzopoulos KM, Pianta MJ, Vingrys AJ, Wilkinson-Berka JL, Kalloniatis M, et al. Angiotensin type-1 receptor inhibition is neuroprotective to amacrine cells in a rat model of retinopathy of prematurity.JComp Neurol. 2010;518(1):41-63. doi:10.1002/cne.22205. [PubMed: 19882719].

15. Ferrer Novella C, Gonzalez Viejo I, Pueyo Royo V, Martinez Fernandez R, Galdos Iztueta M, Peralta Calvo J, et al. [A protocol for the treatment of retinopathy of prematurity in Spain]. Arch Soc Esp Oftalmol. 2013;88(6):231-6. doi: 10.1016/j.oftal.2012.07.028. [PubMed: 23726308].

16. Ferrer Novella C, Gonzalez Viejo I, Pueyo Royo V, Martinez Fernandez R, Galdos Iztueta M, Peralta Calvo J, et al. Screening program for retinopathy of prematurity in Spain. Arch Soc Esp Oftalmol. 2013;88(5):184-8. doi: 10.1016/j.oftal.2012.07.030. [PubMed: 23623019].

17. Ortega-Molina JM, Anaya-Alaminos R, Uberos-Fernandez J, SolansPerez de Larraya A, Chaves-Samaniego MJ, Salgado-Miranda A, et al. Genetic and Environmental Influences on Retinopathy of Prematurity. Mediators Inflamm. 2015;2015:764159. doi: 10.1155/2015/764159. [PubMed: 26089603].
18. Hillman SC, Morris RK, Kilby MD. Single twin demise: consequence for survivors. Semin Fetal Neonatal Med. 2010;15(6):319-26. doi: 10.1016/j.siny.2010.05.004. [PubMed: 20584634].

19. Barba J S, Carvajal C J. Pautas de manejo del embarazo múltiple complicado con la muerte fetal in útero de un gemelo. Revista chilena de obstetricia y ginecología. 2012;77(2):159-68. doi: 10.4067/s071775262012000200014 .

20. Eichenwald EC, Committee on F, Newborn AAOP. Apnea of Prematurity. Pediatrics. 2016;137(1) doi: 10.1542/peds.2015-3757. [PubMed: 26628729].

21. Wade KC, Pistilli M, Baumritter A, Karp K, Gong A, Kemper AR, et al. Safety of Retinopathy of Prematurity Examination and Imaging in Premature Infants. J Pediatr. 2015;167(5):994-1000 e2. doi: 10.1016/j.jpeds.2015.07.050. [PubMed: 26299381].

22. Schneider DJ, Moore JW. Patent ductus arteriosus. Circulation. 2006;114(17):1873-82. doi: 10.1161/CIRCULATIONAHA.105.592063. [PubMed: 17060397].

23. Golombek SG, Sola A, Baquero H, Borbonet D, Cabanas F, Fajardo C, et al. [First SIBEN clinical consensus: diagnostic and therapeutic approach to patent ductus arteriosus in premature newborns]. An Pedi$\operatorname{atr}$ (Barc). 2008;69(5):454-81. [PubMed: 19128748].

24. Gonzalez Viejo I, Ferrer Novella C, Pueyo Royo V, Garcia Martin E, Rite Gracia S, Caballero Perez V, et al. [Is patent ductus arteriosus a risk factor for retinopathy of prematurity?]. An Pediatr (BarC). 2011;74(1):2530. doi: 10.1016/j.anpedi.2010.08.003. [PubMed: 20888311].

25. Goswami B, Goyal M, Beri S, Garg R, Saili A, Jain A. Role of Serum Levels of Vascular Endothelial Growth Factor and Its Receptor in Retinopathy of Prematurity. Iran JPediatr. 2015;25(4):e2373. doi:10.5812/ijp.2373. [PubMed: 26396701].

26. Panfoli I, Cassanello M, Bruschettini M, Colella M, Cerone R, Ravera $S$, et al. Why do premature newborn infants display elevated blood adenosine levels? Med Hypotheses. 2016;90:53-6. doi: 10.1016/j.mehy.2016.03.007. [PubMed: 27063086].

27. International Committee for the Classification of Retinopathy of P. The International Classification of Retinopathy of Prematurity revisited. Arch Ophthalmol. 2005;123(7):991-9. doi: 10.1001/archopht.123.7.991. [PubMed: 16009843].

28. Chiang MF, Thyparampil PJ, Rabinowitz D. Interexpert agreement in the identification of macular location in infants at risk for retinopathy of prematurity. Arch Ophthalmol. 2010;128(9):1153-9. doi: 10.1001/archophthalmol.2010.199. [PubMed: 20837799].

29. Ngo MH, Borowska-Fielding J, Heathcote G, Nejat S, Kelly ME, McMaster CR, et al. Fzd4 Haploinsufficiency Delays Retinal Revascularization in the Mouse Model of Oxygen Induced Retinopathy. PLoS One. 2016;11(8):e0158320. doi: 10.1371/journal.pone.0158320. [PubMed: 27489958].

30. Anaya-Alaminos R, Garcia-Serrano JL, Cantero-Hinojosa J. Prenatal and postnatal factors increase risk of severe ROP. J Matern Fetal Neonatal Med. 2014;27(6):635-6. doi: 10.3109/14767058.2013.818648. [PubMed: 23796013].

31. Lajko M, Cardona HJ, Taylor JM, Shah RS, Farrow KN, Fawzi AA. Hyperoxia-Induced Proliferative Retinopathy: Early Interruption of Retinal Vascular Development with Severe and Irreversible Neurovascular Disruption. PLoS One. 2016;11(11):e0166886. doi: 10.1371/journal.pone.0166886. [PubMed: 27861592].

32. Klevebro S, Lundgren P, Hammar U, Smith LE, Bottai M, Domellof $\mathrm{M}$, et al. Cohort study of growth patterns by gestational age in preterm infants developing morbidity. BMJ Open. 2016;6(11):e012872. doi: 10.1136/bmjopen-2016-012872. [PubMed: 27856479]. 